\title{
Effect of Graphene-Oxide Addition on the Microstructure and Mechanical Properties of Two-Stage Sintered Zirconia-Toughened Alumina (ZTA) Composites
}

\author{
Hsien Loong Teow ${ }^{1}$, Sivakumar Sivanesan ${ }^{1, *}$, Se Yong Eh Noum ${ }^{1}$, Ananthan Soosai ${ }^{1}$ and \\ Suresh Muniandy ${ }^{1}$ \\ ${ }^{1}$ School of Engineering, Taylor's University Lakeside Campus, No. 1 Jalan Taylor's, 47500, Subang \\ Jaya, Selangor DE, Malaysia.
}

\begin{abstract}
United Nations has estimated that 130 million people would suffer from osteoarthritis worldwide by 2050 . This disease would require patients to undergo a surgery known as Total Hip Replacement (THR) which has a failure rate of approximately $1 \%$ with a lifespan of 20 years. The biomaterials used to manufacture this total hip artroplasty are mainly made of Zirconia-Toughened Alumina. In this work, Zirconia Toughened Alumina (ZTA) composites with 10 vol\% Y-TZP content were doped with small amount (0.01 to $1 \mathrm{wt} \%$ ) of graphene oxide (GO). The GO-doped ZTA composites were produced via two-stage sintering with $\mathrm{T}_{1}$ ranging between $1400^{\circ} \mathrm{C}$ and $1550^{\circ} \mathrm{C}$, heating rate of $20^{\circ} \mathrm{C} / \mathrm{min}$, followed by $\mathrm{T}_{2}$ of $1350^{\circ} \mathrm{C}$ and 12 hours holding time. The sintered ZTA samples were then evaluated on its microstructure and mechanical properties such as bulk density, Vickers hardness, Young's modulus and fracture toughness to investigate the effect of GO addition on ZTA samples prepared via two-stage sintering. The results showed that ZTA composites containing up $0.1 \mathrm{wt} \%$ GO is beneficial in improving the microstructural and mechanical properties of ZTA composites prepared via two-stage sintering. The sample recorded a high hardness of up to $18.5 \mathrm{GPa}$, Young's modulus of $406 \mathrm{GPa}$ and fracture toughness of $5.8 \mathrm{MPam}^{1 / 2}$ when sintered at $\mathrm{T}_{1}$ of $1450^{\circ} \mathrm{C}$.
\end{abstract}

\section{Introduction}

Zirconia-toughened alumina (ZTA) composites is a composite material which consist of alumina as its primary phase and Y-TZP as its secondary phase [1]. Y-TZP which also known as yttria-tetragonal zirconia polycrystals, is a material which widely used in various applications in the industry do its excellent flexural strength, inertness and fracture toughness. However, Y-TZP suffers from properties degradation when exposed to hostile environments such as high humidity [2]. On the other hand, alumina does not suffer to from properties degradation upon exposure to hostile environments and possesses high hardness. Nevertheless, alumina does suffer from a weakness which is low fracture toughness [3]. In

\footnotetext{
* Corresponding author: SivaKumar.Sivanesan@taylors.edu.my
} 
order to overcome this weakness of alumina, Y-TZP are added to alumina to form a binary composite known as ZTA [4].

ZTA composites exhibits excellent mechanical properties hence attributing to its wide usage especially in the biomedical field [5-6]. ZTA composites' mechanical properties have been investigated by Kurtz et al. [7] and it was found that this composite does not suffer from low temperature degradation like Y-TZP and it possesses the excellent high fracture toughness of Y-TZP and hardness of alumina. There are multiple researches [8-10] that have been done on the mechanical properties of ZTA composite and the authors have attributed the excellent ZTA's mechanical properties are due to the Y-TZP ability to undergo stress induced transformation toughening. Stress induced transformation toughening is an unique process where within the composite matrix, upon triggered by propagating crack, the martensitically stable Y-TZP's tetragonal grain would transform into stable monoclinic grains that result in retardation of the advancing crack. This would result in enhancement of the ZTA's fracture toughness [11-12]. Besides stress induced transformation toughening, there are few researchers [13-14] that attributed the fracture toughness enhancement of ZTA composite were due to other toughening mechanism such as residual stresses, microcracking and zirconia's distribution within the alumina matrix. The authors [13-14] found that the composites' mechanical properties were improved such as fracture toughness, resistance to subcritical crack and also resistance to ageing degradation.

Two-Stage sintering (TSS) is a sintering method developed by Chen and Wang [15] which involves heating up the materials at a relatively higher temperature known as first stage sintering temperature $T_{1}$ and subsequently continued at lower temperature known as second stage sintering temperature $\mathrm{T}_{2}$ followed by long holding time. The authors [15] successfully produced ultra-fine $\mathrm{Y}_{2} \mathrm{O}_{3}$ powder by employing this method. This method are able to suppress the material's grain growth during the final stage of sintering and therefore capable of producing ceramics with enhanced densification [15]. This sintering method has also been applied to produce ultra-fine powders of other ceramic materials by other researchers [16$18]$.

Another method that are used by other researchers [19-20] to improve the densification besides TSS is to add small amounts of sintering additives known as dopants which leads to improvement of the ceramics' mechanical properties. Addition of optimum GO content as a sintering additives has also shown to be beneficial in improving the mechanical of ceramic materials such as $\mathrm{Al}_{2} \mathrm{O}_{3}-\mathrm{SiCw}$ [21], $\mathrm{Si}_{3} \mathrm{~N}_{4}$ [22], and pure Y-TZP ceramics [23]. A lot of researchers have emphasized on the investigation of ZTA's properties such as density, hardness, young's modulus and fracture toughness which are usually influenced by the microstructure parameters such as grain size, phase transformation and tetragonality factor. Composites on the other hand, investigation on composites sintered via TSS combined with addition of dopants has yet to be widely reported. In this present work, the effect of graphene oxide (GO) as dopants on ZTA composite prepared via TSS are evaluated on its grain size, densification and mechanical properties. The current study would enable manufacturer of total hip artroplasty to produce total hip artroplasty with improved mechanical properties therefore leading to better lifespan of the THR reducing the amount of revision surgery that an osteoarthritis patient has to go through in their lifetime.

\section{Methodology}

Commercially available powders of alumina and $3 \mathrm{~mol} \%$ Y-TZP manufactured by Tosoh, Japan were used in this work. The powders have similar mean particle size of $200 \mathrm{~nm}$ and specific surface area, SSA of $13 \mathrm{~m}^{2} / \mathrm{g}$. The ZTA powders consist of $10 \mathrm{vol} \% \mathrm{Y}$-TZP content were doped with varies amount of graphene oxide (GO) contents of $0,0.05,0.1,0.2,0.5$ and $1 \mathrm{wt} \%$. The slurry of ZTA were prepare through the means of alumina ball milling method 
with ethanol as mixing medium to ensure homogeneity. The slurry were then dried in oven for 20 hours to produce a dried cake. The dried cake were then crushed and sieved using a $212 \mu \mathrm{m}$ mesh to obtain ready-to-press GO-doped ZTA powder. The powders were then pressed into disc with dimension of $20 \mathrm{~mm}$ diameter and rectangular bar with length, width, height of $15 \mathrm{~mm}, 5 \mathrm{~mm}$ and $5 \mathrm{~mm}$ respectively using "Pellet Press Steel Dry Pressing Die Set Mold". The samples were then uniaxially pressed using cold isostatic pressing (CIP) (SXKYYC, China) to ensure homogeneity pressing of the samples. The pressed samples were pressureless sintered in air using TSS sintering method with heating rate of $50^{\circ} \mathrm{C} / \mathrm{min}$ and $\mathrm{T}_{1}$ set between $1400^{\circ} \mathrm{C}$ and $1550^{\circ} \mathrm{C}$ (ModuTemp, Australia). The temperature of $\mathrm{T}_{1}$ were then hold for 1 minute before rapid cooled at $50^{\circ} \mathrm{C} / \mathrm{min}$ to $\mathrm{T}_{2}$ set at $1350^{\circ} \mathrm{C}$ and hold for 12 hours. The sintered samples were ground using silicon carbide papers with grades ranging between 120 to 1200 and subsequently polished using diamond paste of $3 \mu \mathrm{m}$ followed by $1 \mu \mathrm{m}$ to obtain reflective surface for SEM image purposes. The samples' bulk density was measured using water immersion technique based on Archimedes principle (ASTM C37318)[24](Mettler Toledo), and the samples' theoretical density (T.D.) were set at $4.183 \mathrm{~g} / \mathrm{cm}^{3}$ based on the rule of mixture. The hardness of the samples were determined using Vickers indentation method (Vickers Hardness Tester, Shimadzu, Japan) with load of $10 \mathrm{~N}$ applied for 15 seconds. The hardness were measured for ten times and the average values are obtained. Using ASTM C769-15 [25], the Young's modulus of the samples were determined while the fracture toughness of the samples were determined using Eq. (1) proposed by Niihara et al., [26]

$$
\left(\frac{K_{I C} \emptyset}{H_{v} a^{1 / 2}}\right)\left(\frac{H_{v}}{E \varnothing}\right)^{\frac{2}{5}}=0.035\left(\frac{L}{a}\right)^{-\frac{1}{2}}
$$

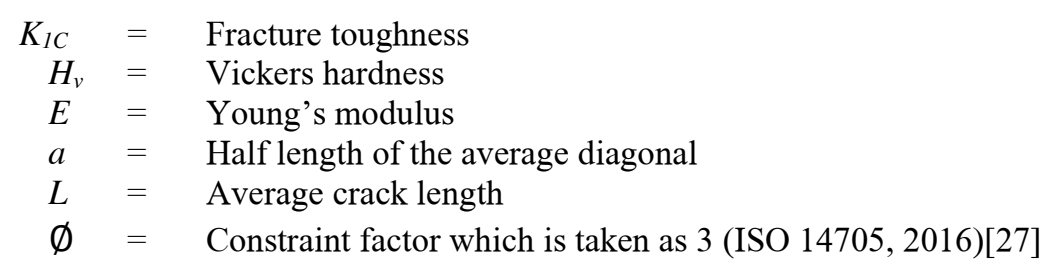

A simple statistical analysis was performed in this study. For each values of the mechanical properties, ten measurements obtained, its mean value and standard deviation was calculated. The average values were then grouped based on the mechanical properties, GO content and its' $T_{1}$ temperature. Graphs were then plotted as shown in Figure 1, Figure 2, Figure 3 and Figure 4. The samples' grain size was determine using line intercept analysis based on the SEM micrographs taken. Five measurements at random locations on the SEM micrographs were taken and the average grain size of the samples are calculated as shown in Table 1.

\section{Results and Discussions}

The bulk density of the undoped and GO-doped ZTA samples are as shown in Figure 1. Based on Figure 1, there were improvement on ZTA samples' bulk density with the addition of GO up to $0.1 \mathrm{wt} \%$. Pure alumina sintered at $\mathrm{T}_{1}$ of $1400^{\circ} \mathrm{C}$ were able to achieve only 96.5 $\%$ T.D. and increased to maximum of only $96.8 \%$ T.D. as $\mathrm{T}_{1}$ increased to $1500^{\circ} \mathrm{C}$. As the GO content increases up to $0.1 \mathrm{wt} \%$, sample sintered at $\mathrm{T}_{1}$ of $1450^{\circ} \mathrm{C}$ was able to achieve 99 $\%$ T.D. As GO content increases beyond $0.1 \mathrm{wt} \%$, there were no improvement in the bulk density as the bulk density fluctuates between $98.7 \%$ to $99.2 \%$. Regardless of first stage 
sintering temperature $\mathrm{T}_{1}$, compared to undoped ZTA samples, bulk density of GO-doped ZTA composite were higher. The improvement of bulk density with addition of up to 0.1 $\mathrm{wt} \% \mathrm{GO}$ can be attributed to the uniform dispersion of GO in the composite matrix of ZTA therefore promoting densification by facilitating the particle arrangement. However, addition of more than $0.1 \mathrm{wt} \%$ GO were shown to be detrimental to the bulk density as drop in bulk density were observed in all samples regardless of $T_{1}$. This is in agreements with the work of few researchers where decrease in bulk density observed in ceramics with higher amount of GO [23,28-29]. The decrease in bulk density as GO content increases beyond $0.1 \mathrm{wt} \% \mathrm{can}$ be attributed to the pores formed due to excessive amount of GO in the composite matrix.

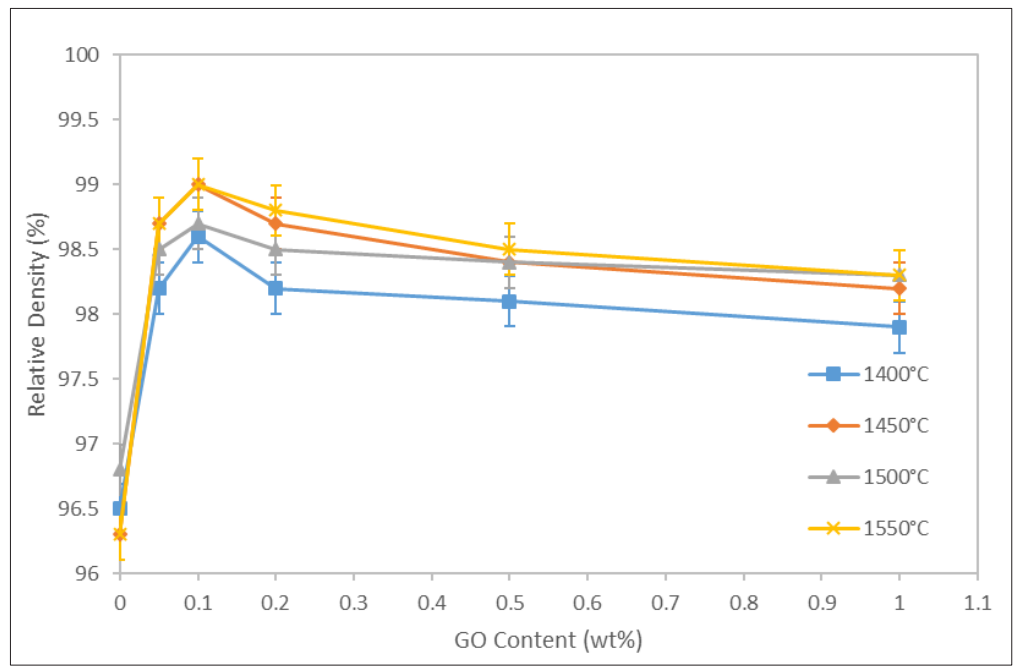

Fig. 1. Bulk density of undoped and GO-doped ZTA composite sintered via TSS at various $\mathrm{T}_{1}$.

The hardness of the undoped and GO-doped ZTA samples sintered via TSS is as shown in Figure 2. Based on Figure 2, the Vickers hardness of GO-doped samples were higher than undoped samples regardless of first stage sintering temperature $T_{1}$. As the GO content increases to $0.1 \mathrm{wt} \%$, an increase of Vickers hardness were observed where maximum recorded were $18.6 \mathrm{GPa}$ for sample sintered at $\mathrm{T}_{1}$ set at $1550^{\circ} \mathrm{C}$. As the $\mathrm{GO}$ content increases above $0.1 \mathrm{wt} \%$, a decreasing trend were observed. This observation correlates well with the bulk density and were observed by other researchers [30-31] as well. The hardness of a ceramic material is greatly influenced by the bulk density as absence of plastic deformation in ceramic material would cause inability for the ceramic material to absorb any energy transferred to the material. Since there is no plastic deformation, once there is a crack that begins to advance, it would continue to advance until the material fracture [32]. The reduction in hardness can be also attributed to the pores formation at higher content of GO in the composite matrix.

The ZTA samples' Young's modulus is as shown in Figure 3. Addition of up to $0.1 \mathrm{wt} \%$ GO has shown to have beneficial effect on the Young's modulus of ZTA. The Young's modulus of undoped samples were recorded to be in the range of $401 \mathrm{GPa}$ at $\mathrm{T}_{1} 1400^{\circ} \mathrm{C}$ to $405 \mathrm{GPa}$ when sintered at $\mathrm{T}_{1}$ of $1550^{\circ} \mathrm{C}$. Highest Young's modulus was observed when the GO content of $0.1 \mathrm{wt} \%$ were present in the composite matrix. Samples with $0.1 \mathrm{wt} \% \mathrm{GO}$ recorded up to $406 \mathrm{GPa}$ when sintered at $1450^{\circ} \mathrm{C}$. However, as $\mathrm{GO}$ content increases beyond $0.1 \mathrm{wt} \%$, the Young's modulus reduces to even lower than of undoped samples. The undoped sample sintered at $\mathrm{T}_{1}$ of $1550^{\circ} \mathrm{C}$ was able to achieve $405 \mathrm{GPa}$ but decreases to $401 \mathrm{GPa}$ as GO content increases to $1 \mathrm{wt} \%$. The reduction in Young's modulus can be attributed to the formation of porosity and microcracks in the composite matrix. The formation of pores and 
microcracks can be caused by the different thermal expansion coefficient of the alumina and graphene oxide in the composite matrix leading to higher porosity in the microstructure of the composite [33].

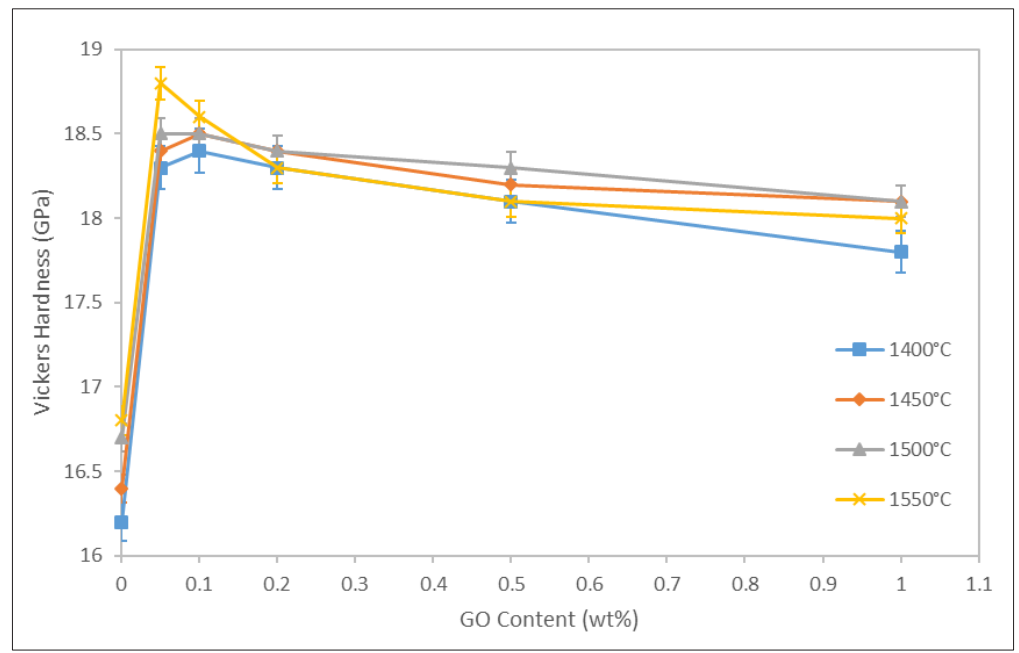

Fig. 2. Vickers hardness of undoped and GO-doped ZTA composite sintered via TSS at various $\mathrm{T}_{1}$.

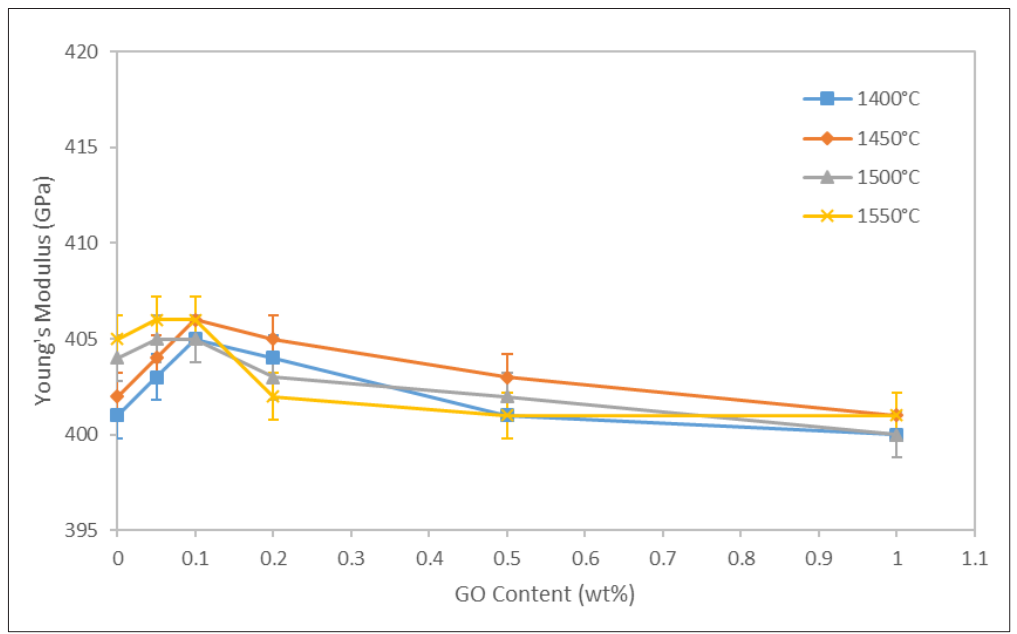

Fig. 3. Young's modulus of undoped and GO-doped ZTA composite sintered via TSS at various $\mathrm{T}_{1}$.

Figure 4 shows the fracture toughness of the undoped and GO-doped ZTA samples. Generally, compared to the undoped ZTA samples, all GO-doped ZTA samples obtained higher fracture toughness value regardless of sintering temperatures of $\mathrm{T}_{1}$ of $1450^{\circ} \mathrm{C}$ with 0.1 $\mathrm{wt} \% \mathrm{GO}$ content attained maximum fracture toughness of $5.8 \mathrm{MPam}^{1 / 2}$. As the GO content increases to $0.2 \mathrm{wt} \%$, reduction of up to $15 \%$ fracture toughness value were observed for all samples regardless of $\mathrm{T}_{1}$. As the GO content increases beyond $0.2 \mathrm{wt} \%$, the fracture toughness value remained relatively constant fluctuating in the range of 4.7 to $5 \mathrm{MPam}^{1 / 2}$. 


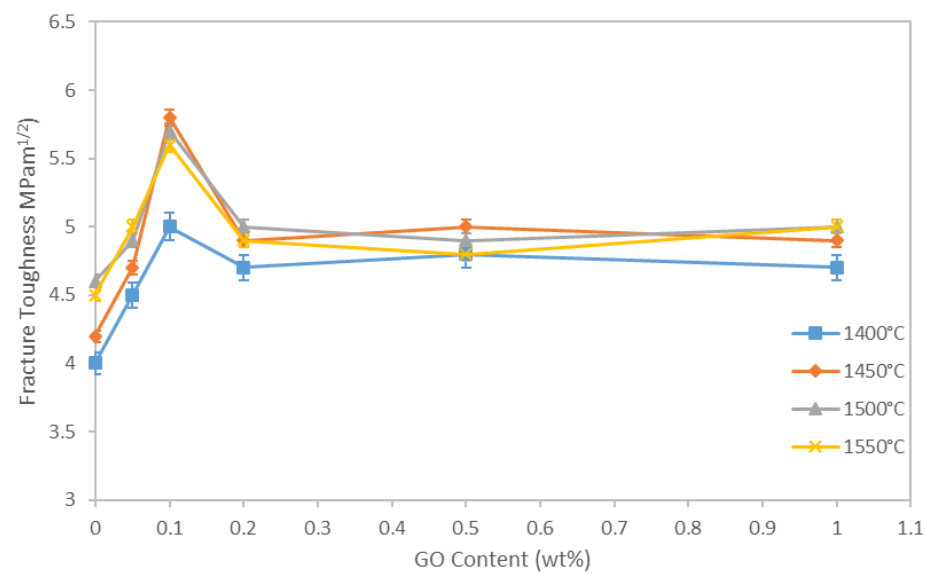

Fig. 4. Fracture toughness of undoped and GO-doped ZTA composite sintered via TSS at various $\mathrm{T}_{1}$

In general, in a composite matrix, the fracture toughness value are influenced by the stability of the tetragonal grains. A tetragonal grain in metastable state would respond immediately upon an advancing crack during indentation and martensitically transformed into stable monoclinic grain and stop the advancing crack resulting in higher fracture toughness. In agreement with the works of Ramesh et al. [23], the addition of GO did not affect stability of the tetragonal grains in the composite matrix.

The grain size of undoped and GO-doped ZTA composites sintered via TSS at $\mathrm{T}_{1}$ of $1450^{\circ} \mathrm{C}$ is as shown in Table 1. The addition of GO into the composite matrix did not affect the grain sizes as the grain sizes were found to be similar regardless of GO content. As the GO content increases, more pores were observed in the composite matrix as shown in Figure 5.

Table 1. The grain size of undoped and GO-doped ZTA sintered via two-stage sintering of $\mathrm{T}_{1}=$

\begin{tabular}{|c|c|}
\hline \multicolumn{1}{|c|}{$1450^{\circ} \mathrm{C}$ and $\mathrm{T}_{2}=1350^{\circ} \mathrm{C}$ and holding time of 12 hours. } \\
\hline GO Content (wt \%) & Average Grain Size $(\boldsymbol{\mu m})$ \\
\hline 0 & 0.52 \\
\hline 0.05 & 0.51 \\
\hline 0.1 & 0.53 \\
\hline 0.2 & 0.52 \\
\hline 0.5 & 0.53 \\
\hline 1.0 & 0.51 \\
\hline
\end{tabular}
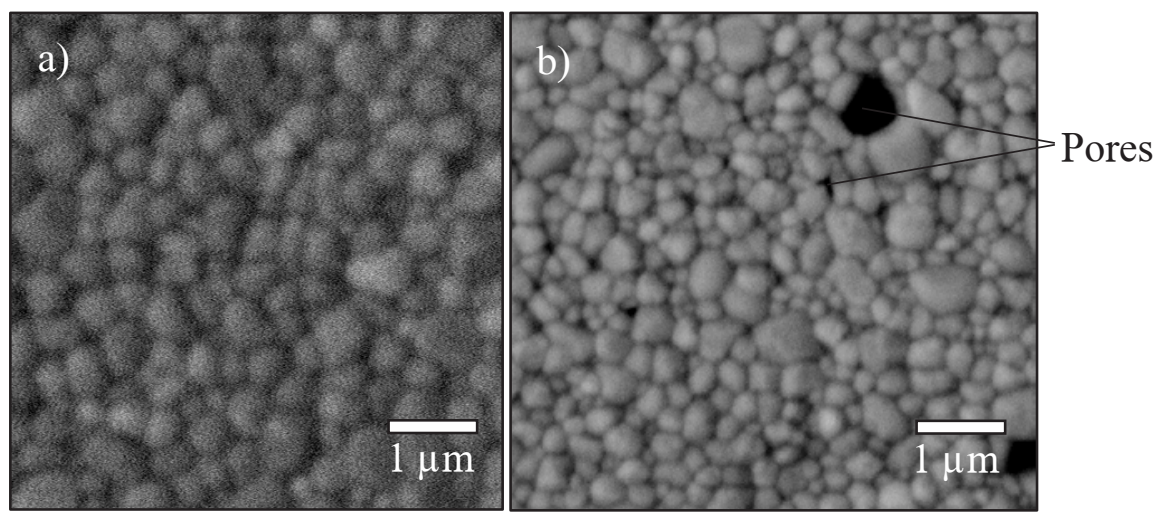

Fig. 5. SEM images of samples sintered at $\mathrm{T}_{1} 1450^{\circ} \mathrm{C}, \mathrm{T}_{2}$ of $1350^{\circ} \mathrm{C}$ with 12 hours holding time a) with $0.2 \mathrm{wt} \% \mathrm{GO}$ content $\mathrm{b}$ ) with $1 \mathrm{wt} \% \mathrm{GO}$ content 


\section{Conclusion}

Addition of GO into ZTA composite matrix was found to be beneficial only up to $0.1 \mathrm{wt} \%$. Addition of GO content beyond $0.1 \mathrm{wt} \%$ has shown to be detrimental to the mechanical properties of ZTA composite with the exception of fracture toughness. Addition of $0.1 \mathrm{wt} \%$ GO content and $\mathrm{T}_{1}$ of $1450^{\circ} \mathrm{C}$ would result in a ZTA composite superior to the undoped ZTA with 99\% T.D., Vickers hardness of $18.5 \mathrm{GPa}$, Young's modulus of $406 \mathrm{GPa}$ and fracture toughness of $5.8 \mathrm{MPam}^{1 / 2}$. This shows that there are possiblities to manufacture ZTA composites that meet or exceed the industrial standards such as ISO 6474 by careful selection of dopants amount and sintering parameters. Furthermore, with the findings of this research, people around the world suffering from osteoarthritis would be benefitted by having a total hip arthroplasty with enhanced mechanical properties and longer lifespan compared to current specifications leading to improved well-being and getting closer to achieving United Nations' Sustainable Development Goal 3 which is to ensure healthy life and promote wellbeing for all at all ages.

\section{References}

1. Y. Sui, L. Han, Y. Jiang, Ceram. Int. 44, 14811-14816 (2018)

2. S. Sivanesan, T. H. Loong, S. Namasivayam, M.H. Fouladi, Key Eng. Mat. 814, 12-18 (2019)

3. T. H. Loong, S. Y. Eh Noum, W. W. Mun, Key Eng. Mat. 861, 327-333 (2020)

4. P. K. Rao, P. Jana, M. I. Ahmad, P. K. Roy, Ceram. Int. 45, 16054-16061 (2019)

5. T. H. Loong, S. Y. Eh Noum, W. W. Mun, Key Eng. Mat. 861, 320-326 (2020)

6. S. Sivanesan, T. H. Loong, S. Namasivayam, M. H. Fouladi, Key Eng. Mat. 814, 340$346(2019)$

7. S. M. Kurtz, S. Kocagoz, C. Arnholt, R. Huet, M. Ueno, W. L. Walter, J. of the Mech. Behav. of Biomed. Mat., 31, 107-116 (2014)

8. H. L. Teow, S. Sivanesan, S. Y. E. Noum, AIP Conf. Proc., 2233, 20028 (2020)

9. J. Fan, T. Lin, F. Hu, Y. Yu, M. Ibrahim, R. Zheng, J. Ma, Ceram. Int. 43, 3647-3653 (2017)

10. H. L. Teow, S. Sivanesan, S. Y. E. Noum, AIP Conf. Proc., 2233, 20029 (2020)

11. A. M. Ali, A. Z. A. Azhar, N. S. Abdullah, M. M. Ratnam, A. Z. Ahmad, Mat. Sci. Forum, 888, 108-111 (2017)

12. N. Yildirim, F. Kern, Sci. of Sinter., 51, 243-256 (2019)

13. D. Blaese, T. Benitez, M. Barros, H. Jelitto, N. Travitzky, D. Hotza, R. Janssen, Ceram. Int., 44, 13463-13468 (2018)

14. P. Tan, P. Wu, L. Gao, Y. Sui, Y. Jiang, Mat. Res. Exp., 6, 65205 (2019)

15. I. W. Chen, X. H. Wang, Nature, 404, 168-171 (2000)

16. X. Ni, J. Zhao, J. Sun, F. Gong, Ceram. Int., 45, 21564-21571 (2019)

17. D. Hong, Z. Yin, S. Yan, W. Xu, Ceram. Int., 45, 11826-11832 (2019)

18. A. Sutthapintu, A. Rittidech, J. of Magnetics, 25, 133-139 (2020)

19. A. M. Hassan, S. M. Naga, M. Awaad, J. of Refrac. Met. and Hard Mat., 48, 338-345 (2015)

20. K. Biotteau-Deheuvels, L. Zych, L. Gremillard, J. Chevalier, J. of the Eur. Ceram. Soc., 32, 2711-2721 (2012) 
21. S. Grigoriev, P. Peretyagin, A. Smirnov, W. Solis, L. A. Diaz, A. Fernandez, R. Torrecillas, J. of the Eur. Ceram. Soc, 37, 2473-2479 (2017)

22. K. Balazsi, M. Furko, P. Klimcyzk, C. Balazsi, Ceramics, 3, 40-50 (2020)

23. S. Ramesh, M. M. Khan, H. A. Chee, Y. H. Wong, P. Ganesan, M. G. Kutty, A. Niakan, Ceram. Int., 42, 17620-17625 (2016)

24. ASTM Int., C373-18 (2018)

25. ASTM Int., C769-15 (2015)

26. K. Niihara, J. of Mat. Sci. Let., 2, 221-223 (1983)

27. Int. Std. Org., ISO705 (2016)

28. Q. Li, Y. Zhang, H. Gong, H. Sun, T. Li, X. Guo, S. Ai, Ceram. Int., 41, 6248-6255 (2015)

29. Y. Yang, B. Li, C. Zhang, S. Wang, K. Liu, B. Yang, Mat. Sci. and Eng., 644, 90-95 (2015)

30. S. M. Naga, A.M. Hassan, M. Awaad, Ceram. Int., 41, 6248-6255 (2015)

31. I. Salehinia, S. Shao, J. Wang, H. M. Zbib, J.O.M., 66, 2078-2085 (2014)

32. R. C. Bradt, C. A. Brookes, J. L. Routbort, Springer Sci. \& Buss. Media (2013)

33. D. Lao, W. Jia, S. Li, D. Hei, R. Chen, Mat. Res. Exp., 6, 105209 (2019) 